\title{
The Attitudes and Behaviors of Pregnant Women about Labor Anesthesia
}

\section{Doğum Analjezisi Hakkında Gebe Kadınların Tutum ve Davranışları}

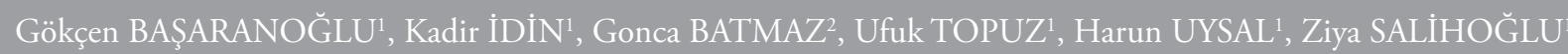 \\ 'Department of Anesthesiology and Reanimation, Bezmialem Vakif University, Faculty of Medicine, Istanbul, Turkey \\ ${ }^{2}$ Department of Obstetrics and Gynaecology, Bezmialem Vakif University, Faculty of Medicine, Istanbul, Turkey
}

\section{ABSTRACT}

Objective: The aim of this study is to analyze pregnant women's knowledge, attitude, and behavior toward labor analgesia.

Methods: Between March 2011 and December 2011, 533 pregnant women who visited an antenatal clinic were administered a survey that measured their attitude, behavior, and knowledge about labor analgesia.

Results: There was no difference between age, pregnancy week, and desire for labor analgesia, but there was a significant difference between the number of pregnancies and desire for labor analgesia.

Women who did not want labor analgesia had more pregnancies, births, and children and a large household. Women who desired labor analgesia had an occupation (64\%); 31\% of pregnant women who did not want labor analgesia considered it unnecessary; $13 \%$ thought it would be harmful to the baby, herself, or the birth process; $2 \%$ found it expensive; $16 \%$ feared it; and $0.5 \%$ found it contradictory to religious beliefs.

Conclusion: Although no prior information was given to the pregnant women who attended the survey, the number of births and education level affected the labor analgesia desire. If labor analgesia is emphasized in formal and common education, this might increase the request for it.

Key Words: Obstetrics, pain-free, labor

\section{ÖZET}

Amaç: Bu çalışmanın amacı doğum analjezisi hakkında gebe kadınların bilgi, tutum ve davranışlarını incelemektir.

Yöntemler: Mart 2011-Aralık 2011 arasında antenatal polikliniğe gelen 533 gebe kadına doğum analjezisi hakkında bilgi, tutum ve davranışlarını ölçen anket uygulandı.

Bulgular: Ankete katılan gebelerin yaşları, gebelik haftası ile ağrısız doğum yapma isteği arasında anlamlı bir fark bulunmazken, gebelerin gebelik sayısı ile ağrısız doğum isteği arasında anlamlı farklılık bulunmuştur. Doğum analjezisini istemeyen kadınların gebelik, doğum sayısı, evdeki çocuk-yaşayan kişi sayısı fazla olup ağrısız doğumu daha fazla çalışan kadınlar (\%64) istemiştir. Gebelerin sadece \%36'sı ağrısız doğum yapmak istemişlerdir. Doğum analjezisini istemeyen gebelerin \%31'i doğum analjezisini gerekli görmezken, \%13’ü bebeğe, kendisine veya doğum sürecine zarar verdiğini düşünmüş, \%2'si pahalı bulmuş, \%17'si korkuğu için, \%0,5'i dini inançlarına aykırı bulduğu için \%36'sı diğer sebeplerden dolayı doğum analjezisini istememiştir.

Sonuç: Anketi dolduran gebe kadınlara doğum analjezisi hakkında hiçbir önbilgi bilgi verilmemesine ragmen doğum sayısı ve eğitim düzeyi doğum analjezisi istemini etkilemiştir. Doğum analjezisi yaygın ve örgün eğitim içinde daha fazla vurgulanabilirse doğum analjezisi istemi artabilir.

Anahtar Sözcükler: Obstetrik, ağrısız, doğum

\section{Giriş}

Doğum ağrısı bir kadının hayatında yaşadığı en ağrılı olaylardan biri olup kültür, çevre, şahsi, sosyal ve psikolojik birçok faktörden etkilenebilir $(1,2)$. Doğumda pekçok analjezik yöntem kullanılabilir. Epidural analjezi, sistemik yoldan intravenöz-intramüsküler analjezi, akupunktur, cilt yoluyla elektriksel sinir uyarılması ile ağrı giderilmesi, releksasyon yöntemleri, hipnoz doğum analjezi yöntemlerinden sadece birkaçıdır (3-5). Doğum analjezisi gelişmekte olan ülkelerde yaygın olarak 


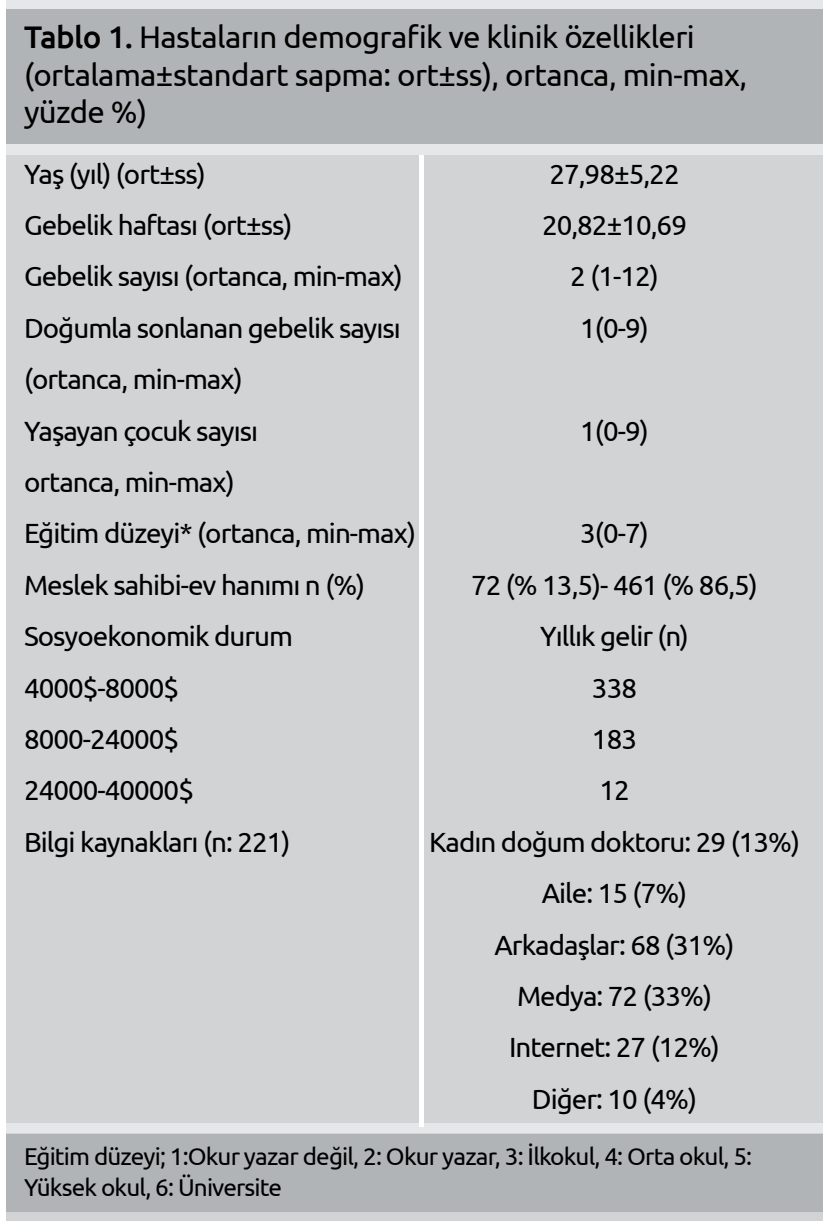

kullanılmakta ise de teknik ve doğum analjezisi uygulayabilecek eğitimli personelin yetersizliği bu yöntemin yeterli ve efektif kullanılmasını sınırlar. Bu çalışmada antenatal polikliniğe başvuran gebe kadınların doğum analjezisi hakkında bilgi tutum ve davranışlarının araştırılması amaçlandı.

\section{Gereç ve Yöntemler}

Mart 2011-Aralık 2011 arasında antenatal polikliniğe gelen gebe kadınlara doğum analjezisi hakkında bilgi, tutum ve davranışlarını ölçen anket B.30.2.BAV.0.05.05/142 sayılı etik kurul alındıktan sonra uygulandı (Ek 1). Anket; 14’ü kişiye özel, diğerleri çoktan seçmeli olan 22 bilgi-tutum sorusu içeriyordu.

\section{İstatistiksel Analiz}

Mean Whitney U ve Pearson Ki-kare testi ile değerlendirildi (IBM, SPSS 19, USA). Ortalama \pm standart sapma olarak veriler verildi. $\mathrm{p}<0,05$ değerleri anlamlı kabul edildi.

\section{Bulgular}

Ankete katılan toplam 533 gebenin yaşı, gebelik haftası, ortalama aylık gelir, eğitim ile ağrısız doğum yapma isteği arasında anlamlı bir fark bulunmazken, gebelerin gebelik sayısı ile ağrısız doğum isteği arasında anlamlı farklılık bulunmuştur $(p<0,05)$. Doğum analjezisini istemeyen kadınların gebelik, rısız doğumu daha fazla çalışan kadınlar istemiştir $(\mathrm{p}<0,05)$. Hastaların \%41,47'si ağrısız doğumu duymuş (n:221) olup bunların büyük kısmı ağrısız doğumu medyadan duymuşlardır. Sadece \%0,4 (n:2) gebeye önceki gebeliklerinde ağrısız doğum uygulanmıştı. Gebelerin sadece \%36'sı ağrısız doğum yapmak istemişlerdir. Hayır diyenlerin \%31'i (n:59) doğum analjezisini gerekli görmezken, \%13’ü (n: 25) bebeğe, kendisine veya doğum sürecine zarar verdiğini düşünmüş, \%2'si (n:4) pahalı bulmuş, \%17'si (n:32) korktuğunu belirtmiş, $\% 0,52$ 'si (n:1) dini inançlarına aykırı bulurken \%36'sı (n:69) diğer sebeplerden dolayı doğum analjezisini istememiş $(54$ kişi doğum analjezisi hakkında bilgi sahibi değil, 12 kişi genel anestezi altında sezeryan olmak istiyor, 1 kişi doğal yollardan ağrı çekerek doğurmak istiyor, 1 kişi felç olma ihtimali olduğunu düşündüğü için doğum analjezisi istemiyor, 1 kişi ağrnya dayanabildiği için doğum analjezisini istemiyor). Ankete katılan hastalardan sadece 20 hastaya daha önceden ağrisız doğum teklif edilmiş. Bu doğumu ağrısız yapmak isteyen hasta oranı ancak \%36'ıydı. Çalışmaya katılan hastaların demografik verileri Tablo 1'de gösterilmiştir.

\section{Tartışma}

Doğum ağrısı bir kadının yaşayacağı en şiddetli ağrı olarak tanımlanmış olup "Amerikan obstetrik ve jinekoloji ve Amerikan anestezi derneğine göre tıbbi bir kontrindikasyon yoksa hasta isteği doğum ağrısını gidermek için yeterli bir indikasyondur (6).

Ağrı hayatı tehtid eden durum değildir, ama postnatal depresyon, posttravmatik stress bozukluğu ile beraber olabilir ve postpartum periyoddaki kognitif fonksiyonlardaki bozulma intrapartum analjeziklerden herhangi biri kullanılarak azaltılabilir (7). Doğum sonrası dönemdeki zihin fonksiyon bozukluğu intrapartum dönemde verilen herhangi bir analjezik ile azaltılabilir $(8,9)$.

Doğum ağrısı kültürel farklılık göstermekte olup bazı ülkelerde kişiler dini inançları gereği doğum analjezisi istemeyebilirler. Hristiyan inancında "Çocuk doğururken sana çok acı çektireceğim. Ağrı çekerek doğum yapacaksın.” şeklinde yazmaktadır (10). Bu nedenle bu din mensuplarının bazıları doğumun ağrı çekilerek gerçekleşmesi gerektiğine inanırlar. Ülkemizde yaşayan halkın çoğunluğu islam dinine mensub olup İslam dini inanışında "doğum sancılarını azaltmak için doktorların önerdiği yöntemleri uygulamakta dinen sakınca yoktur" denilmektedir (11).

Ankete katılan hastaların \% 95, 1'ine daha evvel ağrısız doğum teklif edilmemiş. Ankete katılanların \%41,46'sı ağrısız doğumu duymuş olup medyadan duyan çoğunlukta idi $(\% 32,6)$. Ülkemizde yapılan bir çalışmada doğum analjezisini gebelerin hangi kaynaklardan duydukları sorgulanmıştır (12). Gebe kadınların \% 50'sinin cevabı 1997 ile 1999 yılları arasında medya kaynaklı (televizyon, gazete) olmasına karşın 2000-2002 yılları arasında bu kaynak (\%60) daha evvel epidural analjezi yapılmış kadınların deneyimi olduğudur. Bu da bize doğum analjezisi deneyimi yaşamış olan kadınların sayısının arttığı- 
nı gösterir. Doğum analjezisi bilgisi hakkında yapılan güncel çalışmaların çoğunluğu gelişmekte olan ülkelerde yapılan çalışmalardır. 1977'de Avrupa kaynaklı yapılan çalışmalarda kişilerin akraba ve arkadaşlarından doğum analjezisini duyma oranı fazlaydı. Bizim sonuçlarımızdaki farklılık günümüzde medya ve iletişim araçlarının daha fazla kullanılması ve ülkemizde doğum analjezisinin yaygın olmamasına bağlı olabilir. Şahin ve ark.'nın çalışmasında doğum analjezisinin ülkemizde ancak \%11 oranında yapıldığını ortaya koymuşlardır (13). Bu da çalışmamızda doğum analjezisi deneyimi olan kadınların az olmasının sebebi olabilir.

Pirbudak ve ark. (14) doğumda epidural analjezi kullanımında Türk obstetrisyenlerin bilgi ve tutumlarını gösteren çalışmalarında obstetrisyenlerin çoğunun doğum analjesi eğitimini uzmanlık eğitimi sonrası kurslardan aldığını göstermişdir. Aynı yazarlar epidural analjezi eğitimini en iyi şekilde anestezistler ve obstetrisyenlerin uzmanlık eğitimi ve sonrası eğitimlerinde karşılıklı işbirliği ile birbirlerini desteklemeleri ile iyileştirilebileceğini vurgulamışlardır.

Çalışmamızdaki hastaların ağrısız doğum deneyimi $\% 3$ olup, ağrısız doğum yapmak istemeyenlerin \% 32'si ağrısız doğumu gereksiz bulup \%35'inin gerekçesi diğer nedenlerdi. Ankete katılan gebelerin \%35'i ağrısız doğum yapmak istememişti. Bunlardan \%31'i doğum analjezisinin gerekli olmadığını belirtirken, \%17'si doğum analjezisinden korktuğunu, \%14'ü doğum sürecine ya da kendisine zarar vermesinden endişe ettiğini, $\% 2$ 'si pahalı bulduğunu, $\% 0,53$ 'ü dini inaçlarına aykırı bulduğunu, \%36'sı da diğer sebeplerden dolayı doğum analjezisini istemediklerini belirtmiştir.

Liu ve ark. (15) çalışmalarında sosyoekonomik düzey ile eğitim düzeyi ve doğum analjezisi istemi arasında doğru bir ilişki bulmuşlardır. Çalışmamızda hastalarımızın ortalama geliri ile doğum analjezisi istemi arasında bir fark bulunmamıştır. Hastalarımızın $\% 2,8$ 'i okur yazar olmayıp, $\% 50,5$ 'i orta okul ve öncesi, \%46,7’si lise ve yüksek okul mezunuydu. Hastalarımızın eğitim düzeyi ile doğum analjezisi istemi arasında anlamlı fark bulunmamıştır $(\mathrm{p}>0,05)$.

Literatürde Avrupa kaynaklı doğum analjezisi hakkında yayın kısıtlıdır. Güncel çalışmalar daha çok gelişmekte olan ülkelerde daha çok Hindistan, Nijerya, Pakistan, Afrika kaynaklı olup çalı̧̧mamızda bu ülkelere göre farklıdır (16-20). Bu çalışmamızda eğitim seviyesi, yıllık ortalama gelir ile doğum analjezisi istemi arasında fark bulunmamıştır. Bu da doğuma gelen gebelerin internet ve diğer media kaynaklı yayınları okuyup doğum analjezisinin risklerini bilmelerinden kaynaklanabilir. Bu çalışmalarda doğum analjezisini duyma daha çok eş, dost akraba aracığılığı ile olmaktadır. Ülkemiz Avrupa ile Asya arasında köprü ülke olmakta olup halkın büyük çoğunluğu müslümandır. Dinen doğum analjezisini engelleyen hüküm olmamasına rağmen ankete katılan hastalardan sadece bir tanesi doğum analjezisini dini sebeplerden dolayı redetmiştir. Ankete katılan gebelerin 1/3'ü doğum analjezisini gereksiz bulmuştur.
Anketi dolduran gebe kadınlara doğum analjezisi hakkında hiçbir önbilgi bilgi verilmemesine ragmen doğum sayısı ve evde yaşayan kişi sayısı doğum analjezisi istemini negatif yönde etkilemiştir. Doğum analjezisinin riskleri konusunda gebelerimiz bilgi sahibi olduğu için sonuçlarımız diğer ülkelere kıyasla farklı çıkmıştır.

Çalışmamızın kısıtllılıkları: Gebe kadınlara sadece poliklinikte bu anket yapılmıştır. Gebelere doğum sürecinde ağrı çekerken bu anket yapılmamıştır.

\section{Sonuç}

Yaygın ve örgün eğitim içinde doğum analjezisi daha fazla vurgulanabilirse doğum analjezisi istemi artabilir.

Ethics Committee Approval: Ethics committee approval was received for this study (B.30.2.BAV.0.05.05/142).

Informed Consent: Written informed consent was obtained from patient who participated in this study.

Peer-review: Externally peer-reviewed.

Author Contributions: Concept - G.B.; Design - U.T.; Supervision - K.I.; Funding - G.B.; Materials - H.U.; Data Collection and/or Processing - H.U.; Analysis and/or Interpretation - Z.S.; Literature Review - G.B.; Writing G.B.; Critical Review - Z.S.

Conflict of Interest: No conflict of interest was declared by the authors.

Financial Disclosure: The authors declared that this case has received no financial support.

Etik Komite Onayı: Bu çalışma için etik komite onayı alınmıştır (B.30.2.BAV.0.05.05/142).

Hasta Onamı: Yazılı hasta onamı bu çalışmaya katılan hastalardan alınmıştır.

Hakem Değerlendirmesi: Dış bağımsız

Yazar Katkıları: Fikir - G.B.; Tasarım - U.T.; Denetleme - K.I.; Kaynaklar G.B.; Malzemeler - H.U.; Veri Toplanması ve/veya İşlemesi - A.S.; Analiz ve/ veya Yorum - G.B.; Literatür Taraması - G.B.; Yazıyı Yazan - G.B.; Eleştirel İnceleme - Z.S.

Çıkar Çatışması: Yazarlar çıkar çatışması bildirmemişlerdir

Finansal Destek: Yazarlar bu çalışma için finansal destek almadıklarını beyan etmişlerdir.

\section{Kaynaklar}

1. Weber SE. Cultural aspects of pain in childbearing women. J Obstet Gynecol Neonatal Nurs 1996; 25: 67-72. [CrossRef]

2. Callister LC, Khalaf I, Semenic S, Kartchner R, Vehvilainen-Julkunen K. The pain of childbirth: perceptions of culturally diverse women. Pain Manag Nurs 2003; 4: 145-54. [CrossRef]

3. Cyna AM, McAuliffe GL, Andrew MI. Hypnosis for pain relief in labour and childbirth: a systematic review. Br J Anaesth 2004; 93: 505-11. [CrossRef]

4. Nesheim BI, Kinge R. Performance of acupuncture as labor analgesia in the clinical setting. Acta Obstet Gynecol Scand 2006; 85: 441-3. [CrossRef] 
5. Evron S, Ezri T. Options for systemic labor analgesia. Curr Opin Anaesthesiol 2007; 20: 181-5. [CrossRef]

6. American College of Obstetricians and Gynecologists: ACOG Committee Opinion n. 295: Pain relief during labor. Obstet Gynecol 2004; 104: 213. [CrossRef]

7. Hiltunen P, Raudaskoski T, Ebeling H, Moilanen I. Does pain relief during de- livery decrease the risk of postnatal de- pression? Acta Obstet Gynecol Scand 2004; 83: 257-61. [CrossRef]

8. Eidelman AI, Hoffmann NW, Kaitz M. Cognitive deficits in women after child- birth. Obstet Gynecol 1993; 81: 764-7.

9. Hawkins JL. Epidural analgesia for labor and delivery. N Engl J Med 2010. 22; 362: 1503-10. [CrossRef]

10. Bible Hub. Genesis 3:16. http://bible.cc/genesis/3-16.htm.

11. Din İşleri Yüksek Kurulu Başkanlığı. Dini Soruları Cevaplandırma Formu. https://kurul.diyanet.gov.tr/SoruSor/SoruKodundanSoruArama.aspx. Din işleri yüksek kurulu soru cevaplandırma platformu, soru kodu: 5E48825D-7F9B-48FB-AFD8-F3612C71C012.

12. Pirbudak L, Balat O, Tuncer S, Oner U. Evaluation of the knowledge andattitude of obstetric patients on epidural analgesia. Agri 2004; 16: 64-8

13. Sahin S, Owen M. Obstetric analgesia and anaesthesia in Turkey and in the World. Journal of the Turkish Anaesthesiology and Reanimation Society 2002; 30: 52-59.
14. Pirbudak L, Balat O, Kutlar I, Uğur MG, Sarimehmetoğlu F, Oner U. Epidural analgesia in labor: Turkish obstetricians' attitudes and knowledge. Agri 2006;18: 41-6.

15. Liu N, Wen SW, Manual DG, Katherine W, Bottomley J, Walker MC. Social disparity and the use of intrapartum epidural analgesia in a publicly funded health care system. Am J Obstet Gynecol 2010; 202: 273. [CrossRef]

16. Ibach F, Dyer RA, Fawcus S, Dyer SJ. Knowledge and expectations of labour among primigravid women in the public health sector. $S$ Afr Med J 2007; 97: 461-4.

17. James JN, Prakash KS, Ponniah M. Awareness and attitudes towards labour pain and labour pain relief of urban women attending a private antenatal clinic in Chennai, India. Indian J Anaesth 2012; 56: 195-8. [CrossRef]

18. Minhas MR, Kamal R, Afshan G, Raheel H. Knowledge, attitude and practice of parturients regarding Epidural Analgesia for labour in a university hospital in Karachi. J Pak Med Assoc 2005; 55: 63-6.

19. Barakzai A, Haider G, Yousuf F, Haider A, Muhammad N. Awareness of women regarding analgesia during labour. J Ayub Med Coll Abbottabad. 2010; 22: 73-5.

20. Ogboli-Nwasor E, Adaji S, Bature S, Shittu O. Pain relief in labor: a survey of awareness, attitude, and practice of health care providers in Zaria, Nigeria. J Pain Res 2011; 4: 227-32. 


\section{Ek 1: Ankette sorulan sorular}

1. Hasta Adı:

2. Hasta Yaşı:

3. Gebelik Haftası:

4. Kaçıncı Gebelik:

5. Yaptığı Doğum Sayısı:

6. Yaşayan Çocuk Sayısı:

7. Eğitim Durumu:

Okur-yazar değil: 1

Okur-yazar: 2

İlkokul: 3

Ortaokul: 4

Lise: 5

Üniversite: 6

Yüksek Lisans: 7

8. Meslek:

Ev Hanımı: 1

İşç: 2

Memur: 3

Serbest Meslek: 4

Diğer: 5

9. Halen Çalışıyor Musunuz?

Evet: 1

Hayır: 0

10. Yaşadığınız Ev

Kendimize ait: 1

Kira: 2

Aileme ait: 3

Diğer: 4

11. Evinizde Kaç Kişi Yaşıyor

2:1

$3: 2$

$4: 3$

$5: 4$

5 ten fazla : 5

12. Evinize Giren Ortalama Aylık Gelir (maaş,kira,vb. dahil)

500 TL'den az: 1

501-1000 TL: 2

1001-2000: 3

2001-3000: 4

3001-4000: 5

4001-5000: 6

5001 TL'den fazla

13. Nerelisiniz?

Marmara Bölgesi: 1

Karadeniz: 2 
Bezmialem Science 2014; 2: 65-70

Ege: 3

Akdeniz: 4

İç Anadolu: 5

Doğu Anadolu: 6

Güneydoğu Anadolu: 7

14. Kaç Yıldır İstanbul'da Yaşıyorsunuz?

İstanbul'da Yaşamıyorum: 1

1 Yildan Az: 2

1-5 Yil: 3

5-10 Yil: 4

10 Yıldan Fazla: 5

15. Ağrısız Doğumu Duydunuz Mu?

Evet: 1

Hayır: 0

16. Ağrısız Doğumu Nereden Duydunuz?

Doktorumdan: 1

Ailemden: 2

Komşu/Arkadaş: 3

Medya: 4

İnternet: 5

Diğer: 6

17. Daha Önceki Doğum(lar)nızda Size Ağrısız Doğum Teklif Edildi mi?

Evet: 1

Hayır: 0

18. Daha Önce Ağrısız Doğum Yaptınız mı?

Evet: 1

Hayır: 0 (19.soruya geçiniz)

19. Ağrısız Doğumdan Memnun Kaldınız mı?

Evet: 1

Hayır: 0

20. Ağrısız Doğumu Yakınlarınıza Tavsiye Eder misiniz?

Evet: 1

Hayır: 0

21. Bu Doğumunuzu Ağrısız Doğum Yöntemiyle Yapmayı Düşünür müsünüz

Evet: 1

Hayır: 0

22. (Yanıt Hayırsa) Neden

Gerek Yok: 1

Korkuyorum: 2

Dini İnancıma Aykırı: 3

Pahalı: 4

Bebeğe, Doğum Sürecine Ya Da Bana Zararı Olabilir: 5

70 Diğer (Belirtiniz): 6 